\title{
The Representations of Stephen Hawking in the Biographical Movies
}

\author{
(10) João Fernandes, ${ }^{(0)}$ Guilherme da Silva Lima, ${ }^{(1)}$ Orlando Aguiar Jr.
}

\begin{abstract}
Keywords Abstract This article aims to analyze two biographical films of Stephen Hawking; Stephen Hawking in order to identify the representations of the Representation of scientist present in cinematographic works. For this, the investigation scientist; was based on film analysis and categorization following the main Movies; representations identified in the literature. The analysis identified the Scientific culture. most common representations present in the scenes and sequences in which the protagonist acted, taking into account the context for certain actions of the scientist. The results indicated that the analyzed works, which belong to a biographical genre, are also bound to permeate stereotypes that contribute to a distorted view of the scientist and scientific work, just as it happens in other cinematic genres.
\end{abstract}

\section{Introduction}

Science correlates with several different spheres of human culture, in a way that it is possible to find literary, plastic, scenic and cinematic works that make reference to the scientific universe. Such references are not based exclusively on specific issues of science and technology culture (STC); quite the contrary, they can appropriate themes, processes, languages, history, among other scientific and technological elements. This work considers as elements of scientific culture all human productions that interact with activities, processes, concepts, history and any other aspects of scientific and technological activity, even when produced in frontier territories, such as science fiction.

Interfaces between STC and art occur for several reasons, among which we highlight both the interest of society in scientific themes and the appropriation of science and technology themes by the cultural industry. Currently, we can see several scientific and technological themes that have instigated and instigate great interest in society, such as genetic mutation, interplanetary travel, artificial intelligence, global warming. 
The relations between artistic production and STC have already been discussed by several researchers (Cunha \& Giordan, 2009; Ferreira \& Raboni, 2013; Ramos \& Piassi, 2017; Zanetic, 2006) to indicate either boundaries and interactions between these activities or possibilities of using such relations to promote scientific education.

A very relevant example of the interaction between science and art is the production of the film Le voyage dans la Lune (A trip to the Moon), directed by Georges Méliès and released in 1902, which linked cinematic work, scientific knowledge and the literary works From Earth to the Moon and The First Men in the Moon, written some time before by Jules Verne and Herbert Wells, respectively (Roberts, 2016).

The cinema has been tied to STC since the beginning, as it not only addresses related themes and practices, but also depends on the development of new tools and techniques for the production of films. The seventh art (as cinema is also known) has developed as a form of entertainment with its own characteristics, whose most striking feature is the presentation of moving images. It appropriated social practices and "quickly assimilated elements from all human knowledge. The greatness of cinema is that it is a sum, as well as a synthesis of several other arts"1 (Sadoul, 1963, p. 7), thus promoting changes in the ways in which reality and fiction are represented artistically.

The cultural industry has appropriated the scientific imaginary to produce films, books, images, etc. With that, it also promotes activities that contribute to the production of this imaginary. Thus, STC is not exclusively a possible source, but also a target for the products of cultural industry and, in particular, for cinematic productions.

In this sense, STC can be understood as a product generated from different sources. Thus, the perceptions and conceptions that individuals create about science and technology are based on different media supports (television and radio programs, films, articles and interviews in newspapers and magazines, etc.), in addition to conversations with friends and family and the school, conception that is classified as a network model in the field of public communication of science (Polino \& Castelfranchi, 2012). Cinema, in turn, is configured as a support capable of fostering the perception and imagery of STC elements.

Understanding STC through the network model means not only to deconstruct the idea that there is a center that produces this culture, but also to consider social exchanges as integral parts of STC production and therefore of the scientific imaginary. When we relate the network model to cinematic production, we can see the influence that cinema has on the maintenance of culture and the imaginary itself through the representation of scientific activities and their agents.

Bearing in mind that the scientific imaginary is determined collectively, cinematic works both produce and reproduce characteristics that make up this imaginary. In this sense, analyzing cinematic works can indicate relevant aspects of the relationship between cinema and scientific imaginary.

1 TN: All quotations in Portuguese have been translated into English. 
This paper aims to analyze two biographical films by Stephen Hawking in order to emphasize the forms and contexts in which the scientist's representations are presented in the works "Hawking" and "The Theory of Everything". In order to outline clear guidelines for the investigation, we proposed the following questions: how and in what contexts are the representations of Stephen Hawking presented?

To answer these, we resorted to a case study with a qualitative approach. The films were analyzed using a combination of techniques that include considerations about the nature of cinema, content analysis for films (Penafria, 2009) and historical triangulation.

It is important to highlight the relevance of analyzing biographical cinematic works, since the fields of investigation (science education, cultural studies and science communication) that ramp up efforts to understand the relationships between cinema and science generally do not focus on this cinematic genre. Science fiction and documentary are the main investigated genres. In this sense, the study of biographies can expand the understanding of the field with regard to the interfaces between cinema and science. It is worth remembering that biographical works in cinema should not be interpreted as a reliable representation of the character's story, but as a point of view, which, in addition to the story, contains artistic elements and effects to promote entertainment. Accordingly, the study of these works can also indicate critical forms for their use in educational contexts.

The choice to make a work centered on representations of Stephen Hawking is based on the relevance that the physicist and cosmologist had and still has, both in scientific production and in scientific dissemination. Through his theories and books, Stephen Hawking became known worldwide for formulating a theory about the beginning of the universe that corroborates the Big Bang Theory. In 1966, Hawking stated in his doctoral thesis that in the beginning all matter was condensed into a singularity, just like black holes (Hawking, 1993). Later, in 1974, Hawking made another contribution to the understanding of black holes by theorizing that not everything is confined to them and that radiation is expelled from their nuclei (Hawking, 1975). These are just some of Hawking's contributions to science, and it is just not appropriate to list them all out.

Another point that contributed to Hawking's international fame was the publication of several science communication books. "A brief history of time", from 1988, became the biggest best seller in the category, having sold more than 25 million copies until 2007 (McKie, 2007). His initiative to create instruments that could take science beyond academia also motivated researchers in the field to look at his works. In short, Hawking was able to break the barriers between STC and society, in addition to motivating researchers from different fields of knowledge (Grego, 2013).

We also highlight the importance of the discussion about the interfaces between STC and art for the field of science education, as the scientific formation of subjects and society does not occur exclusively through formal education. Informal education is a determining process in science education, which is sometimes neglected. The consumption of cinema and other artistic and communicational productions can 
contribute to scientific training as it addresses scientific themes, while disseminating values and ideas. According to Smith (2001), informal education is understood as a

truly lifelong process whereby every individual acquires attitudes, values, skills and knowledge from daily experience and the educative influences and resources in his or her environment - from family and neighbours, from work and play, from the marketplace, the library and the mass media.

In addition to their role in informal education, films have great potential as a tool in a teacher's arsenal for science education. In the case of the works chosen for analysis, the biographical films about Stephen Hawking can contribute to the introduction of themes of modern physics, especially cosmology, in educational situations. Several researchers of science education indicate the potential of cinema for the field. Such contributions are predominantly focused on the use of science fiction (Cunha \& Giordan, 2009; Piassi, 2013; Piassi \& Pietrocola, 2009; Santos \& Silva, 2017) and, to a lesser extent, documentaries (Barbosa \& Bazzo, 2013; Cazón \& Oliveira, 2018; Marcelo \& Ripoll, 2016).

Among the contributions to science education, we highlight Piassi and Pietrocola's (2009) proposal that presents alternatives that go beyond the traditional use of cinema in teaching situations, which is usually focused on finding and addressing conceptual errors in films. The authors proposed a method for analyzing the content of science fiction films in which counterfactual elements present may have different uses in science education. In turn, Alcântara and Lima (2018) used the methodology of a film debate to bring the community closer to the STC. The authors identified categories of scientific and technological elements present in cinematic works that can be used for the selection and analysis of films in situations of scientific education.

The importance of using cinema in teaching situations is not exclusively related to the development of school content. Cunha and Giordan (2009) emphasize that "A film in the classroom should serve as an object of study, as the school needs to critically mediate aspects of everyday culture in the school context, in order to intervene positively in the interpretation of the media" (p. 15-16). Such consideration becomes more pertinent as we understand that the relationship between a cinematic work and the STC indicates "science as culture within the sociocultural context of a society" (Piassi, 2013, p. 531).

We believe, therefore, that the two films that portray Stephen Hawking's biography can be used in many different ways in formal and/or informal science education: a) introduction to cosmology; b) discussion of scientific work; c) problematization of the scientist's image represented in the films.

\section{The image of scientists in cinema}

Representations of scientists are present in several other artistic and communicative activities and contribute as much as cinema to the production of the image of the scientist in society, which is the subject of several researches, such as Almeida and Lima (2016), 
Gorp et al. (2013), Long et al. (2014), Marcelo and Ripoll (2016), Reznik and Massarani (2019), and Scalfi and Oliveira (2015). Ultimately, these images and representations can contribute to producing profiles of science and technology perception, as well as to the consolidation of collective memory, making people en masse appropriate certain interpretations of reality.

According to Perez (2012), the images and representations that a group of society makes, in order to categorize patterns of an object, person, profession etc., is called a stereotype. For the author, "the stereotype is a way to simplify our worldview, saving time and energy when making certain generalizations" (p. 885). Although the definition of stereotype has different nuances for each author, what resembles them is that it is a "shared belief about attributes - personality traits or behaviors - of groups of people" (Rodrigues et al., 1999, p. 150)

Weingart et al. (2003) contribute to the investigation of the representation of scientists in films. When analyzing 222 Hollywood science fiction films, the authors point out that the scientists are Caucasian (96\%), male (82\%) and American (49\%). They further claim that the appearances of scientists are discreet and caricatured. Such results consolidate the representations of science as a male career marked by the eccentricity of appearance. Similar results were also found by Ramos and Olschowsky (2009) in animated films.

The predominance of men does not exclude the representation of female scientists. Jackson (2011) investigated the representation of female scientists in alternative horror films. When analyzing 17 films, the author points out that the representation of the scientist as mad is portrayed in four films, in addition to two others that indicate that the scientist may develop madness later in their life. Despite being part of a common representation of the scientist, this result is not usual for the representation of the female scientist, as pointed out by Flicker (2003):

The cliché description of "mad scientist" does not apply to women scientists. They do not work in hidden laboratories on dubious projects but rather, remain solid 'with their feet on the ground.' Female characters in feature films do not contribute to the build up of negative myths surrounding the image of science. (p. 316)

Flicker (2003) also highlights that in the characters depicting female scientists the professional stereotype is overlaid by a gender stereotype. Therefore, scientists in films do not represent the scientific rationality often represented by figures of male scientists. Instead, female scientists rescue intuition, emotion and feelings.

Weingart et al. (2003) try to go beyond the recurrent representation of the mad scientist, although this is predominant. One of the other representations identified by the authors is that of the benevolent scientist, which does not imply the absence of contradictions and ambivalence. According to the researchers, in this type of representation scientists can be characterized as easily manipulated; idealists who become corrupt; ambitious and willing to violate ethical principles for the sake of knowledge or 
career. Such results indicate antagonisms in the representations of the scientist, a result that is compatible with the considerations of Oliveira (2006), who highlights that

the images and representations of science and its representatives in the films are fluctuating and can be disparate. Scientists are, for example, stereotyped simultaneously as cunning and naive, humble and overbearing. In the analysis of the scientific imaginary, however, the coexistence of opposite representations does not necessarily mean dissonance (Oliveira, 2006, p. 148).

In addition to science fiction, documentaries (another film genre) also produce representations of scientists. Gingras (2007) analyzes the documentary on La relativité, Poincaré et Einstein, Planck, Hilbert: Histoire véridique de la théorie de la relativité (Relativity, Poincaré and Einstein, Planck, Hilbert: A True history of the theory of relativity), released in 2004, which questions Einstein's appropriation of Poincarés contributions to the development of the special relativity theory. In his results, the author highlights the representation of Poincaré in the film: a lone, disorganized and genius scientist ${ }^{2}$, who contributed to several fields of knowledge, characteristics that fit into the most common representations that create the image of scientists.

The representations of scientists in cinema sometimes disregard the social and cultural contexts that permeate their personal activities, so that both science fiction films and documentaries do little to portray the private aspects of their lives (Gingras, 2007; Weingart et al., 2003). For one thing, Poincaré "is presented as a pure mind floating in the world of Platonic numbers, while technology and society pass as a mere background" (Gingras, 2007, p. 371). Such characteristics are justified by the film producers' own agendas (Gingras, 2007), which may be based on the coercions of the cultural industry, which sometimes emphasizes dramatization and capturing the public. Such considerations can be extended, without causing many problems, for science fiction films.

These contributions outline the main representations of scientists present in films throughout history, especially that of a mad scientist, while the genre that most addresses scientific themes is Terror (Weingart et al., 2003).

Considering the social transformations that have occurred in recent decades, we next consider the criticism of Haynes (2016), who claims that "since 2001, we have learned to fear most the terrorism and fanaticism arising from political systems and fundamentalism and, underpinning them, the unpredictable madness of despotic or fanatical leaders" (p. 42). As a result, part of the fears arising from modernity and the post-war period, which were predominantly associated with scientific and technological development, remain in the background.

Haynes (2016) maintains that the representation of scientists has been revised since the beginning of the 21st century. Barca (2005) found that there was a significant change: in the 1960s, the scientist was a central figure in feature films, acting, especially,

2 All mentions of the term "genius" are used to refer to characters in the story who do not need to make great efforts to attain their intellectual achievements. 
as the villain; in the mid-1980s, this figure took on a secondary role, but the development of the narrative was based on the achievements of groups of researchers; in the early 2000s, the scientist resumed their role as a protagonist, this time as a hero, extolling their physical and manual characteristics, as if all scientific knowledge was just a complement to their natural attributes. Such results indicate the relevance of works like this, as it contributes to understanding this new representation.

Barca's work shows how the scientist's image in cinema can vary historically. In this sense, we understand that the image of the scientist can change according to social transformations, which can determine new ways to represent them. However, It is important to emphasize the predominance and maintenance of certain stereotypes that are based on gender and ethnic prejudices, having as main reference the fact that most scientists are represented as white men (Flicker, 2003; Weingart et al., 2003).

Considering both the transformations in scientists' representation in the 21st century and the diverse social transformations that question the images and social roles of human beings, we want to understand the representations of a world-renowned scientist in biographical films.

\section{How to analyze Hawking and the theories of everything?}

It is important to point out that the representations of scientists indicated in the literature are based predominantly on science fiction. We recognize the differences between science fiction and biopics (object of analysis of this article). It is worth mentioning two points: after the 1970s, the hybridization of cinematic genres becomes recurrent in films (Johnston, 2011), including both analyzed works, which recognize the existence of fictional scenes; 2 . There are few investigations that analyze biopics and their relationship with STC, which is not true for science fiction. Still with these considerations in mind, the approximation between scientists' representations in science fictions and biopics leads us to the following problem: would the categories proposed for analyzing science fiction films also be appropriate for analyzing biographical films? To answer this question, we must examine the nature of the characters in science fictions and biopics.

The first point to be highlighted is the nature of the fictional character. Candido (1968) states:

That sounds like a paradox, but characters are fictional beings. In fact, how can a fiction be? How can something nonexistent come into being? However, literary production rests on this paradox, and the problem of verisimilitude in novels depends on this possibility of a fictitious being, that is, something that, being a creation of fantasy, communicates the impression of the most existential truth. We can say, therefore, that the novel is based, first of all, on a certain type of relationship between the living being and the fictional being, manifested through the character, who is the concretization of it (p. 32). 
This means that the fiction character is not an imaginary production fundamentally separated from reality. Candido (1968) clarifies that "the character must give the impression that they live, that they are like a living being. Therefore, they must remember a living being, that is, maintain certain relations with the reality of the world" (p. 39). The author presents an overview of the characters already produced in the literature and points out that "in the technical evolution of the novel there was an effort to compose whole and coherent beings, through fragments of perception and knowledge that serve as a basis for our interpretation of people" (Candido, 1968, p. 36). Thus, the character in fiction is a production that brings together aspects of reality, in a way that their characteristics and personality can be interpreted as syntheses of human characteristics.

On the other hand, biopic characters should not be interpreted as reliable images of reality, that is, they should not be seen as a mirror of the person represented. From the perspective of historiography, Schmidt (2014) presents important considerations about biography, arguing that it is necessary to consider that

A biography is always a possible among many other constructions about a character, and never "the" definitive portrait. In this sense, it needs to renounce the search for a social or psychological essence that explains the trajectory examined, to take into account the changes of route, the setbacks, the mishaps, the possibilities of each existence (p. 199).

In this sense the biography should not be seen and analyzed as the character's true story, but as a hybrid genre between reality and fiction. Therefore, while it is able to synthesize important moments in the story and the character's experiences, it also recreates and adds fictional elements to the composition of the work. Thus, in a biographical work, the character will never be a full representation of a person.

Candido (1968) contributes to this discussion by emphasizing the impossibility of transposing a real person into the novel:

Could the character then be transposed from reality so that the author could reach this goal? In other words, can a living being be copied into the novel and thus fully enjoy its reality? Not in an absolute sense. First, as we have seen, it is impossible to capture the totality of a person's way of being, or even to know them; second, because in this case artistic creation would be dispensed; third, because, even if it were possible, such a copy would not allow that specific, different and more complete knowledge, which is the raison d'être, the justification and charm of fiction. (p. 39)

From all that has been said, we understand that fiction and biopic characters are a combination of real and fictional elements. Therefore, we consider the pertinence and coherence of the use of proposed categories to analyze science fiction films to analyze biographical films.

This investigation used a qualitative approach, whose research methodology 
included a combination of techniques such as considerations about the nature of cinema, content analysis for films (Penafria, 2009) and historical triangulation, restricted to relevant scientific moments in Hawking's life.

The first film analyzed in this work was "Hawking" (Martin, 2004). This feature film was produced by BBC, in order to depict Stephen Hawking's visit to Cambridge University. The film was based on real and documented accounts, although, according to the producers, some scenes were invented to bring together the events of the cosmologist's life.

The second film, "The theory of everything" (Marsh, 2014), was produced by Universal Studios. In order to portray part of Hawking's life, the film was based on the book that Jane, his first wife, wrote - "Traveling to infinity: My life with Stephen". Although it was based on this book, the film was produced by a company recognized for a business model that Hollywood has always operated under. In this sense, we said from the beginning that the work could contain certain elements due the pressures of the cultural industry and this production model.

When discussing the methodology of analysis of motion pictures (films), Rose (2013) highlights the need to not reduce this record to the prominence of the text. The production of audiovisuals includes several elements that produce meanings (such as lighting, framing, the soundtrack, the sequence, the elements present in the scene, etc.), and therefore cannot be neglected. According to Rose (2013),

audiovisual media are a complex amalgamation of meanings, images, techniques, scene composition, scene sequences and much more. It is, therefore, essential to take this complexity into account when undertaking a content and structure analysis. (p. 343)

Such considerations illustrate the complexity of film analysis. For this work, it was not possible to carry out an analysis that considered all the different elements contained in the films. However, we tried to take account of essential elements in the production of meanings that are related to the representation of scientists, in particular: the scene, the sequence, the soundtrack and the text.

Penafria (2009) points out that when content analysis is applied to film research, it consists of identifying the central theme and breaking it down based on what the film says about the theme. This theme usually relates to issues that are not explicit in the film, but that can be brought to the analyst's reality.

So, we carried out a triangulation of the scientist's history with the books "Stephen Hawking, a life in science", written by Michael White and John Gribbin (2002), and "Stephen Hawking, his life and work", written by Kitty Ferguson (2011) and revised by Hawking himself. This technique was used in order to strengthen the interpretation of stereotypes present in the films. On the other hand, we emphasize that since the films were created for the purpose of entertainment and art (the main purposes of cinema), they do not have the obligation to represent the facts faithfully. In addition, biographies may also contain stereotyped representations of Hawking, as they portray a possible 
story (Schmidt, 2014). In this sense, this paper should not be interpreted as belonging to the fields of history and philosophy of science ${ }^{3}$.

The analyses were performed from the separation of scenes and sequences that showed representations of Hawking. According to Suppia (2015), the concepts of scene and sequence are confused because there are no clear and widely adopted definitions by the community. We decided to adopt Vsevold Pudovkin's conception that the "sum of the shooting-script is divided into sequences, each sequence into scenes, and, finally, the scenes themselves are constructed from a whole series of pieces (script-scenes) shot from various angles" (1983, p. 57, cited in Suppia, 2015). Based on this definition, we separated scenes and sequences that directly or indirectly showed the representations related to Stephen Hawking. In the analysis we present some transcriptions of dialogues that support a certain action that can be classified in the scope of some representation.

Guided by this methodological orientation, we analyzed the narrative dynamics, the points of view expressed in the film and the selected scenes and sequences, according to the following route: analysis and thematic decomposition of the films; selection of scenes and sequences that have evidence of representations of the scientist; descriptive analysis of scenes and sequences to identify the representations present. Therefore, the analyses were performed based on the representation of the scientist in a given scene or sequence. We recognize that this methodological choice may not be able to contemplate aspects related to his personality, since a certain behavior may be associated with situations experienced by Hawking that led him to make decisions that he might not have taken under other conditions. Thus, to try to contemplate the nuances of the scientist's choices, the films were analyzed again trying to capture the historicity and the context on stage up to the selected scene or sequence. We highlight situations that we consider most relevant to the analysis, such as the reasons and contexts involved.

The analysis was carried out so that the most recurring representations according to the literature could be identified (Flicker, 2003; Gingras, 2007; Jackson, 2011; Oliveira, 2006; Weingart et al., 2003), namely: antisocial; disturbed; Caucasian; with a discreet and caricatured appearance; confused (although being a genius); unorganized; eccentric; brilliant; mad; man; lone; benevolent, but with diverse ambivalences; easily manipulated; idealist who corrupts; ambitious; willing to violate ethical principles in favor of scientific knowledge; alienated from the real world. We emphasize that the categories found in the literature served as an initial analysis plan, but that the research sought to identify other representations beyond these.

We emphasize that the analysis presented seeks to go beyond the cataloging of representations present in the films. We consider that understanding the contexts and the reasons that led the character to make a certain decision is more important than knowing which stereotype is represented. This interpretation is based on the fact that the viewer does not passively absorb the meanings and values expressed in the film, but, on the

3 We recognize that the dialogue with the history and philosophy of science can present new nuances and contribute to the critical analysis of works in film and possible uses in science education. However, this dialogue is beyond the scope of this article. We indicate this possibility as an alternative for future investigations. 
contrary, establishes relationships between the facts represented and seeks to interpret the scenes, meanings and values present in the work. We emphasize that, although the cataloging of stereotypes has been relevant to understand the forms of representation of the scientist, we take care not to make isolated interpretations, in order to avoid wrong or misleading analyses of the subjects who work in STC. Thus, we defend the need to move towards understanding the contexts and reasons that guide the character's actions, since these, more than the stereotype category, can be interpreted and reproduced by the viewers. Understanding the contexts and motives of the character's actions can indicate more elements to understand the reasons for the stereotyped interpretations of scientists by the spectators, as they allow the production of a rationally justified representation

\section{Hawking}

The film "Hawking" portrays the physicist's early years as a $\mathrm{PhD}$ student at Cambridge University, during the process of preparing and defending his doctoral thesis. According to the producer (BBC), the cinematic work was based on videos and texts of the time, although it points out that some scenes were invented to fill gaps between events.

The work has three narrative threads that run in parallel. The first and main one represents Stephen's scientific life, focusing especially on his contributions during his $\mathrm{PhD}$, with a special focus on the clash between the Steady-State and the Big Bang Theory, with which Stephen corroborated his theoretical findings. The second narrative addresses the progression of Hawking's disease. This approach does not take up much screen time, but presents decisive moments in the scientist's life. The third narrative, in turn, presents an interview with Arno Penzias and Robert Woodrow Wilson, who in 1965 detected background radiation, which was fundamental for the consolidation of the Big Bang Theory. Social relations with family, friends and with Jane, his future wife, who did not establish relations with career development or with the science theme, are rare in the film, which led us to consider that there is no fourth narrative thread. As the objective of the work is to investigate the representation of the scientist, the excerpts analyzed below are extracted predominantly from the narrative about Hawking's career development.

In Figure 1 we present a table of the scenes/sequences analyzed, with the time stamp and a brief description. 
Figure 1. Scenes and sequences from the film "Hawking"

\begin{tabular}{|c|c|c|}
\hline $\begin{array}{l}\text { Scene/ } \\
\text { Sequence }\end{array}$ & Time & Description \\
\hline 1 & $\begin{array}{l}2: 30- \\
8: 13\end{array}$ & $\begin{array}{l}\text { Stephen's birthday party. The physicist is initially alone in the living room, } \\
\text { then talking to Jane, his future wife. }\end{array}$ \\
\hline 2 & $\begin{array}{l}8: 13- \\
10: 28\end{array}$ & $\begin{array}{l}\text { Medical appointment. After stumbling and unable to stand during his birthday } \\
\text { party, Stephen is taken to the doctor. }\end{array}$ \\
\hline 3 & $\begin{array}{l}27: 47- \\
31: 33\end{array}$ & $\begin{array}{l}\text { Meeting with friends at the bar. Hawking is challenged by one of his friends to } \\
\text { flirt with a girl using only the theory of relativity. }\end{array}$ \\
\hline 4 & $\begin{array}{l}36: 32- \\
39: 11\end{array}$ & $\begin{array}{l}\text { Debate with Hoyle in the corridors. After the interview Stephen and Hoyle } \\
\text { discussed the Steady-state Theory. }\end{array}$ \\
\hline 5 & $\begin{array}{l}40: 15- \\
43: 23\end{array}$ & $\begin{array}{l}\text { Lunch with Stephen, Penrose, Sciama and his wife. During this lunch, the four } \\
\text { talk about different interpretations of time. }\end{array}$ \\
\hline 6 & $\begin{array}{l}43: 38- \\
47: 15\end{array}$ & $\begin{array}{l}\text { Investigation of Hoyle's work. Stephen analyzes the mathematical calculations } \\
\text { of Hoyle's work to find holes. }\end{array}$ \\
\hline 7 & $\begin{array}{l}47: 15- \\
51: 21\end{array}$ & $\begin{array}{l}\text { Disputation of Hoyle's work. Hawking criticizes Hoyle's work amid a } \\
\text { presentation by the cosmologist at the Royal Society. }\end{array}$ \\
\hline 8 & $\begin{array}{l}63: 13- \\
64: 49\end{array}$ & $\begin{array}{l}\text { Gathering in a Jazz bar. Stephen, Jane and a friend of them, whose name was } \\
\text { not mentioned, get together in a Jazz bar. }\end{array}$ \\
\hline 9 & $\begin{array}{l}68: 52- \\
72: 30\end{array}$ & $\begin{array}{l}\text { Insight at Cambridge station. Upon returning to the University, Stephen has } \\
\text { an insight into his research while sitting on the train. }\end{array}$ \\
\hline
\end{tabular}

The representation of Stephen first take place at his birthday party, where his future first wife, Jane Wilde, was present. We can see that the physicist was out of place in the sense that he was at an event that is not usual in classic representations of scientists, who highlight these subjects as antisocial and introverted. Despite the context, elements referring to Hawking's social isolation are prominent, as right in the first scene of this sequence he was alone in a room watching Professor Hoyle, a cosmologist who defended the Steady-state theory, on television talking about scientific subjects related to his future thesis. Another interesting element is the action of the scientist's mother, Isobel, who sought to guide his behavior during the party, an action that is manifested in the character's speech: "[Isobel] Stephen! It's a party. People might want to dance. You can't dance to Wagner". Furthermore, it is evident from this sequence that Hawking interacted exclusively with three people: Isobel, Jane and Frank Hawking, his father. Therefore, these elements reveal representations related to social isolation and inappropriate behavior (perhaps extravagance or eccentricity).

Another point to highlight in the first sequence is that Stephen was presented as representative and maintainer of scientific discourse, since the main dialogue established was about the universe and the Galilean revolution (history of science). At the end of the same dialogue, the discursive object became music, a moment when the scientist demonstrated a sense of humor and relaxation. 
In the following sequence (2), the scientist was again represented as maintainer of scientific discourse. During his first visit to the doctor, due to the first signs of his illness, the director of the film intends to convey the image that the character saw scientific concepts in any dialogue, even the most trivial and mundane. This idea may lead to the interpretation that Hawking was unable to maintain a long dialogue that did not return to science and his future doctoral thesis.

Representing Stephen as anti-social and introverted was reinforced until the 28th minute of the film, as his friends were not mentioned, which seems to emphasize the idea that scientists are lone geniuses. In the third sequence (3), in which his friends show up, they challenged him: the protagonist should conquer a girl using only Einstein's theory of relativity, which reinforces the idea that scientists can only talk about science and are unable to talk on general matters. Finally, in this four-minute sequence, Stephen was able to identify a note on the subject of his doctorate during the flirtation challenge.

This scene, when analyzed in isolation, indicates a representation that scientists can only communicate through science. However, when we consider the social context in which the character is inserted, the interpretation may be different. The cosmologist was challenged by a theoretical physicist, whose name has not been revealed. Thus, we cannot say that the scientist spoke only about science, since he was subjected to this situation. Another reason that may have led the cosmologist to accept the bet is related to the provocations that the colleague made, before the challenge, in relation to the discoveries of cosmology, claiming that these did not serve the "real world".

At 36 minutes (sequence 4), during a recording, possibly an interview or material for science communication with Fred Hoyle, Stephen and Dennis Sciama, his advisor, were watching and discussing possible topics for his research and talking about the Steady State theory, a topic addressed by Hoyle. During the conversation, Stephen questioned this theory, considering that it eliminated the possibility of the beginning of the Universe, and indicated that the Big Bang theory could be coherent. Upon hearing this, Hoyle, who had already finished recording and was walking down the hall next to Sciama and Hawking, strongly criticized the Big Bang theory. With a sarcastic and arrogant narrative, he ridiculed the cosmologist on the grounds that the Big Bang theory was something of a cartoon: "[Hoyle] The thing about the idea of a Big Bang theory is that it's wrong. Irrational and wrong. It's my term, Big Bang. I made it up. Do you know why I called it that? Because it sounds like a cartoon. Big Bang theory is cartoon physics". Hoyle then sarcastically claimed that the Big Bang model supports the existence of God. During the sequence, Stephen listened to him attentively, as he followed him down the hall, but unlike Stephen's conversation with Sciama, he did not express a word.

After 40 minutes of the film (sequence 5), Stephen was again represented as a maintainer of scientific discourse during a lunch. During the meal, Hawking, Penrose, Sciama and his wife talked especially about the weather, alternating moments of relaxation. The sequence is accompanied by classical music, which is silenced as soon as Hawking expresses the problem of the Theory of the Stationary State, whose negation 
was essential for the development of his thesis. The elaboration of the questioning occurs unexpectedly and indicates the mistake of the theory that explained the functioning of the universe defended by Hoyle.

At 43 minutes (sequence 6), Stephen was portrayed investigating Hoyle's work, in order to find errors that could substantiate his criticism, a process that appears to have lasted only one night. Representations like this suggest that scientists are geniuses who, similar to the myth of Isaac Newton and the apple, can come up with several theories promptly and with minimal effort. The representation as a genius was reinforced during the lunch portrayed in sequence 5, in which Penrose made reference to Mozart's genius: "Mozart went to sleep and woke up with an entire symphony in his head without having the slightest idea how he got there". We understand that the film intends to produce the sense of genius attributed to Hawking in a way analogous to the myth of Mozart.

After finding the misconceptions of the Theory of the Stationary State, Stephen participated in a lecture at the Royal Society, where Hoyle's article was presented (sequence 7). After the presentation, Hawking made a strong criticism, alleging that Hoyle's math was wrong in his work, which implied the nullity of the Theory of the Stationary State. According to the film, the dialogue took place as follows: "[Stephen] Your calculation is wrong. The advanced field diverges. [Hoyle] The advanced field does not diverge. [Stephen] I'm afraid it does. It's all wrong. [Hoyle] Would you like to tell us how you know this, young man? [Stephen] I worked it out". It can be noted that, despite being substantiated, the criticism was made without the presentation of calculations, showing that the scientist believed he had the truth on his side. This interpretation is strengthened by the production of the scene, which was composed by the arrangement of three planes. In the first, Hawking was filmed on his back at the highest place in the amphitheater while Hoyle was in the center of the platform in the lowest position. The plan was also composed of several other researchers who attended the lecture, although Hawking was the only one to interact and the only spectator who was standing during the sequence.

Figure 2. Hawking questioning Hoyle

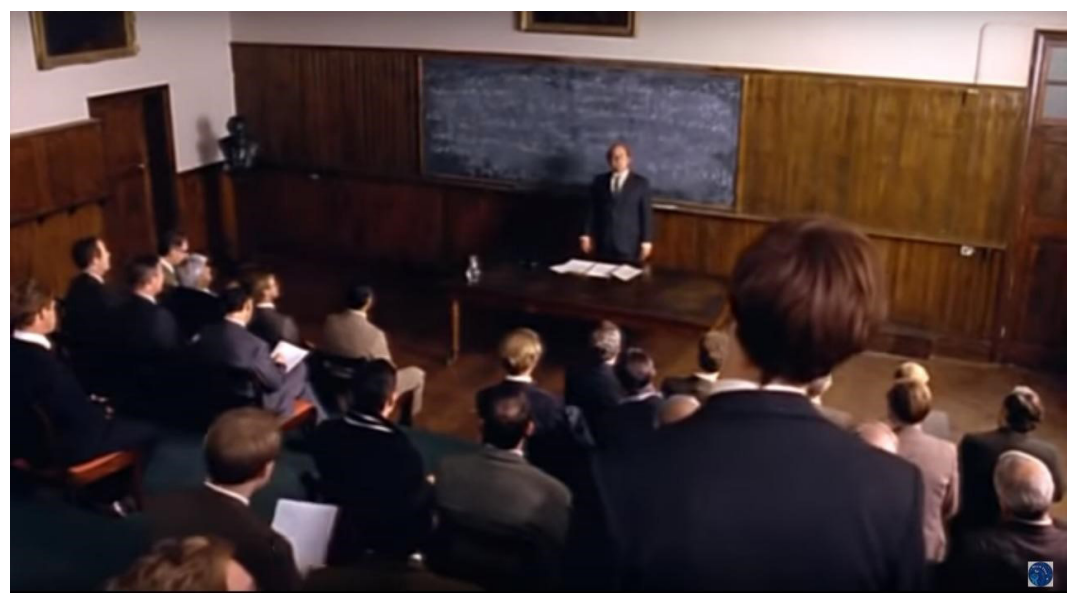


The following plans were composed by the close-up of Hoyle and Hawking, allowing an interpretation of a discussion between peers, with a controversy between equipollent voices, as we see below:

Figure 3. Hoyle's response to Hawking's question

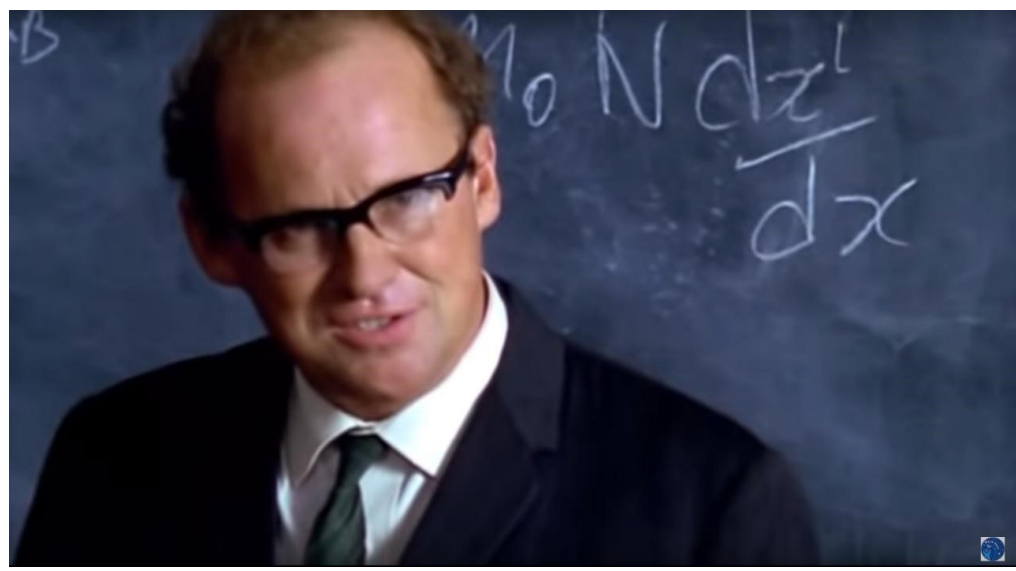

Figure 4. Hawking's replica to Hoyle

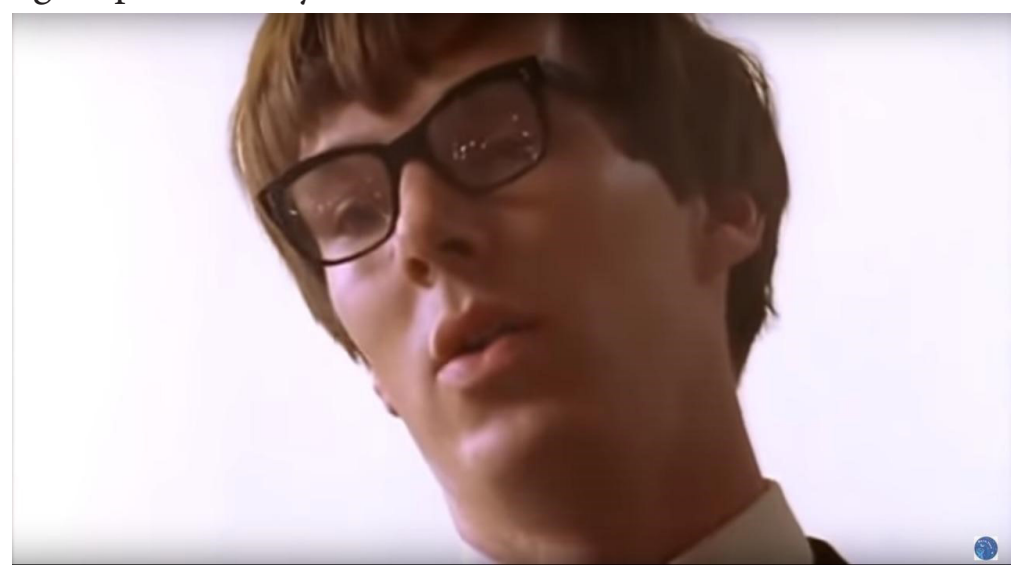

Figure 2 shows an effect in which the image of Hawking seems larger than the image of Hoyle and ends the silence imposed by Hoyle on Stephen in the sequence (4), between 38 and 39 minutes of the film. The fact that Hawking stood up can produce meanings, since the scene took place after a sequence marked by the following moments: 1. Stephen's silence, 2. the elaboration of the problem, 3. the review of Hoyle's work and 4. the confrontation of theories. These moments strengthen the representation of genius, especially since scientific development was presented in a linear, unexpected way and without the representation of an intense work by Stephen.

In his book on Hawking's biography, Ferguson (2011) wrote about this lecture. Stephen's office in the department of applied mathematics and theoretical physics was next to the office of Jayant Narlikar, a student and co-author of Hoyle's work on the steady-state theory. The two physicists met on a summer course before Hawking moved to Cambridge University and talked about the work being done. Although Hawking did the calculations himself, this was not done in just one night, as the film shows. The 
lecture took place as it was portrayed in the film, including the "I worked it out" said by Hawking as the main argument to contradict Hoyle. According to Ferguson (2011):

Unaware that Hawking and Narlikar had discussed the results many times and that Hawking had done calculations of his own, Hoyle and the audience assumed that this unknown research student had 'worked it out' in his head right there at the lecture. The audience was impressed; Hoyle was infuriated. Surprisingly, Hawking seems not to have lost the friendship of Narlikar. In any case, his reputation for brilliance and brashness had begun, and so had his interest in calculations and speculation having to do with the expanding universe.

The comparison between the sequence and the story presented by Ferguson indicates the equivalence of representation and history regarding the questioning of Hoyle's theory, while suggesting that there was the erasure of relevant contexts that guided Stephen in his work, such as their interaction with Narlikar. Although the film showed a subject handing over Hoyle's work to Hawking, that character was not even named, much less the film indicated that there was a friendship or a interaction between them in the research.

At 63 minutes (sequence 8), a new representation of Hawking was produced. During a night in a Jazz bar, the scientist exhibited inappropriate behavior, composed of arrogance and eccentricity, followed by an act of disruption in the narrative. The representation took place when Stephen and Jane were alone at a table watching other people dance, without a previous context explaining the subject, so the conversation came up isolated from the film's narrative:

"[Stephen] The blue lights are picking up the fluorescence you get in washing powder. That's why their shirts are illuminated. [Jane] They're very strange! [Stephen] The dresses are new. They haven't been washed, so they're not fluorescent. There you are, you see? Great scientist. I can tell you all about how washing powders react under blue light. One of the great questions of our time. Whether Tide or Daz is under blue lights. Do you want to dance? [At that moment Stephen leaves the table towards the dance floor without waiting for Jane's response]".

Hawking's words mixed irony and sarcasm to underestimate scientific concepts that he considered less important to a great scientist. This representation comes close to the image of mad and eccentric, which is very common, as it appears in several films and television series with scientific characters such as Sheldon Cooper, in "The Big Bang Theory"; Doctor Brown, from the "Back to the future" saga; Rick, from the animated series "Rick and Morty", among others. This type of behavior was not represented in other sequences of the film, although it can also be understood as a result of Stephen's personal moment. When analyzing the context of his act, we noticed that the sequence appears shortly after the scientist is informed about his illness diagnosis and irreversibility. Therefore, the behavior occurred when Stephen was experiencing a moment of stress, 
both due to the pressure of the doctorate and the informed diagnosis.

The movie ends after 70 minutes, when Stephen was returning from London to Cambridge, after a conversation with Penrose (sequence 9). Inside the train, he sat in front of a lady who started a dialogue about the perception of movement considering the movement of the next train in the opposite direction. Observing the movement of the other train, the lady said: I thought that was us. [Stephen] So did I. [Madam] But it wasn't. [Stephen] No, it was them". Then she continued the conversation by talking about the platform where they boarded the train, known as the Cambridge Platform, and the strange things happening there. When the mechanism clicked and the train jerked backward, Hawking began to realize that his thesis should be based on the reversal of time. Then Stephen got off the train and ran, calling for Penrose, who had taken him there. Stephen explained his formulation, defending the use of Penrose's proposal, which explained the singularity of collapsing stars to understand the beginning of the Universe, a fact that would corroborate the Big Bang Theory. His "Eureka"4 moment was replaced by a "Bang" moment, an expression used by Stephen when his theory dawned on him. These representations are also similar to the Archimedes myth, when he had to solve a problem proposed by the king of Syracuse, which allows us to include them in the same genius representation.

According to White and Gribbin's (2002) book, Hawking's idea of the beginning of the universe did not happen that way. The authors claim that, during the several trips to King's College, where Penrose was giving his lectures, Hawking, Sciama, his advisor, and other students discussed the mathematics involved in the course. One day, on the way back to Cambridge, they were in a second-class compartment on the train talking about the lecture, when Stephen lost his thoughts as he looked at the fields shrouded in darkness. Suddenly he had an idea, which he shared with his advisor: "I wonder what would happen if we applied Roger's theory of singularity to the entire Universe". Arriving in Cambridge, Hawking dedicated himself to this idea and worked like never before. According to the physicist: "I... started working hard for the first time in my life. To my surprise, I found I liked it. Maybe it is not really fair to call it work" (Hawking, quoted in White and Gribbin, 2002).

Another element that reinforces the representation of genius is the presence of the scientist's solitary work, since all theoretical formulations occurred without the direct participation of other researchers. Although the sequence was represented with the participation of Penrose, he did not have a decisive participation in the dialogue, figuring as a mere listener to whom Stephen explained his theory. During the production of his doctoral thesis, Hawking worked alone and showed the work to his advisor only after it was completed. In a conversation between Stephen, Sciama and Penrose, Sciama claimed: "The first three chapters, nothing special". However, when talking about the fourth chapter, Penrose interrupted him by saying "Mozart", resuming the idea of genius presented in the sequence with a lunch between the three scientists.

4 Expression used by the scientist Archimedes de Siracusa (287 B.C.-212 B.C.) when discovering/formulating the Archimedes principle. 
We also point out that all of Hawking's creative moments were accompanied by classical music, which also produces meanings, especially when associated with the popular belief that the taste for classical music is linked to intelligence. Also known as the Mozart effect, this belief is based on the idea "that exposure to classical music (especially Mozart's music) improves intelligence" (Bangerter \& Heath, 2004, p. 606). After an extensive investigation of the origin and evolution of the Mozart effect, Bangerter and Heath (2004) classify it as a scientific legend. They point out that "the Mozart effect is ubiquitous in American culture, where the media and various interest groups quickly saw it as a new and easy technique for improving intelligence" (Bangerter \& Heath, 2004, p. 609), a fact that, according to the authors, can also be observed in other countries. Based on this, we understand that classical music is an effect used by directors to highlight Stephen's intelligence and genius, since this association is common in several countries.

\section{The theory of everything}

The film "The theory of everything", unlike "Hawking", portrays a longer period of the cosmologist's life - from his time at Cambridge University to his refusal of a knighthood granted by Queen Elizabeth. Another striking difference is the source of information - while the first film seeks to weave a narrative based on documentary records, this one was based on Stephen's first wife's perceptions. The feature film was very successful, being nominated for an Oscar in the categories of best actor, best actress, best film, best original soundtrack and best adapted screenplay, making Eddie Redmayne (Stephen Hawking) the best actor of 2015.

"The theory of everything" also has three narrative threads, which are sometimes intertwined. The first and main narrative thread depicts Stephen's fight against Amyotrophic Lateral Sclerosis (ALS). As it is a work that presents a longer period of the scientist's life, there are representations of different phases of the development of ALS and how Hawking managed to overcome the difficulties imposed by physical limitations. The second narrative thread follows Stephen's main scientific achievements, including some of the awards received. The third narrative line addresses Hawking's love relationships, especially with his first wife, Jane Wilde. The three narrative lines sometimes intersect, indicating relationships between the career, the evolution of the illness and the scientist's love life. As the objective of this work is to analyze the representation of the scientist, the following analyses are based mainly on the narrative about Hawking's career.

In the same way as in the previous film, we organized the scenes/sequences in a table, along with duration and a brief description.

5 As we have not been granted copyright permission, no images are presented during the analysis. 
Figure 5. Scenes and sequences from the film "The Theory of Everything"

\begin{tabular}{|c|c|c|}
\hline $\begin{array}{l}\text { Cena/ } \\
\text { Sequência }\end{array}$ & Duração & Descrição \\
\hline 1 & $\begin{array}{l}2: 11- \\
4: 20\end{array}$ & $\begin{array}{l}\text { Party at the University. During a student party in Cambridge, Jane meets } \\
\text { Hawking, a moment when they exchange ideas. }\end{array}$ \\
\hline 2 & $\begin{array}{l}7: 59- \\
12: 26\end{array}$ & $\begin{array}{l}\text { Ten "impregnable" questions. Stephen does a job considered impossible } \\
\text { in a short time. }\end{array}$ \\
\hline 3 & $\begin{array}{l}15: 50- \\
17: 10\end{array}$ & $\begin{array}{l}\text { May Ball in Cambridge. Stephen explains why men's shirts and ties react } \\
\text { to black light. }\end{array}$ \\
\hline 4 & $\begin{array}{l}20: 32- \\
22: 06\end{array}$ & $\begin{array}{l}\text { Idea about research. The cosmologist has an idea about his research when } \\
\text { looking at a pattern formed on the surface of his latte. }\end{array}$ \\
\hline 5 & $\begin{array}{l}22: 57- \\
24: 21\end{array}$ & Theory formulation. Stephen works out the math for his theory. \\
\hline 6 & $\begin{array}{l}27: 35- \\
30: 13\end{array}$ & $\begin{array}{l}\text { Refusal of help. Given the way with which the illness strikes him, Hawking } \\
\text { drives his friends away. }\end{array}$ \\
\hline 7 & $\begin{array}{l}39: 40- \\
42: 24\end{array}$ & Doctoral defense. Stephen defends his thesis. \\
\hline 8 & $\begin{array}{l}42: 24- \\
44: 52\end{array}$ & $\begin{array}{l}\text { Celebrating doctoral graduation. Stephen celebrates with his friends after } \\
\text { he passed his doctoral defense. }\end{array}$ \\
\hline 9 & $\begin{array}{l}48: 11- \\
49: 28\end{array}$ & $\begin{array}{l}\text { Idea about Hawking Radiation. After trying to put on a sweater by himself, } \\
\text { Stephen has an idea about a new type of radiation. }\end{array}$ \\
\hline 10 & $\begin{array}{l}49: 28- \\
53: 03\end{array}$ & $\begin{array}{l}\text { Presentation of his new theory. Hawking presents his theory to a group of } \\
\text { researchers at the Royal Society. }\end{array}$ \\
\hline 11 & $\begin{array}{l}100: 28- \\
105: 07\end{array}$ & $\begin{array}{l}\text { Argument between Jane and Stephen. The couple argues after Hawking } \\
\text { warns that he will go to the US to receive yet another award. }\end{array}$ \\
\hline
\end{tabular}

The film begins with a party at the University of Cambridge. The first lines by Jane Wilde's friend, whose name was not mentioned, demonstrated the perception of a common representation of scientists, that they are boring and dull: "I know everyone here who's... Brilliant! Oh, dear. Scientists. Don't worry, we don't have to stay for long. Looks mortifyingly dull". However, Stephen was represented surrounded by friends, sociable, which breaks with a traditional representation of scientists.

At 8 minutes (sequence 2), his roommate Brian reminded the protagonist, a newbie doctoral student, that he should work through an exercise that contained "ten impossible questions". Within hours Stephen responded to nine of them, while his classmates could not respond to more than one in a week. The solving part took place in a scene where Stephen had just woken up, still wearing his pajamas and using a pamphlet with train schedules to write the solutions because he had not found suitable material on his messy desk. This representation was the first sign that Hawking would be presented as a genius. We emphasize that the scene in which Stephen solves the problems was accompanied by a classical music that is replayed in moments that represent Hawking's scientific development. As in the film "Hawking", there is the intention of the producers 
of "The theory of everything" to associate classical music with intelligence, like the scientific legend of the Mozart effect.

At 15 minutes (sequence 3), Stephen took Jane to the May Ball, a traditional celebration held at Cambridge University. During the prom sequence in which Stephen refused to dance, the physicist explained to Jane why men's shirts and ties shine more than women's dresses when exposed to black light. Then he also talked about what it would be like to observe the universe from the perspective of ultraviolet light. This is a behavior that corroborates the stereotype that scientists seek refuge in science to maintain a dialogue, that is, the film makes a representation that Stephen is a maintainer of scientific discourse.

When the film returned to the cosmologist's career - at 20 minutes (sequence 4) -, he was in a lecture by the mathematician Robert Penrose, who was talking about the first Black Hole Theory. At the end of this lecture, the physicist had an idea regarding his $\mathrm{PhD}$ theme. The decision occurred when Stephen was on the train returning to Cambridge. Sitting in a chair in front of a table with a cup of coffee, he said: "[Hawking] I wonder what would happen if you applied Penrose's theory about black holes to the entire universe". Among the significant elements of the scene, Stephen slowly poured milk into a cup with coffee, forming a white circle in the black background, an image that resumed the drawing made by Penrose with white chalk on the blackboard during the lecture (previous sequence).

This event is portrayed in both films in different ways. As mentioned, Hawking was not alone during this moment of insight. Although in "The theory of everything" the moment was more faithful to the biographies, the sequence does not present the people who accompanied him, which favors the stereotype of genius, since the physicist did not discuss his idea with anyone.

In the following sequence (sequence 5), Hawking explained his idea to Jane, in a moment composed both by the protagonist's scientific development and by the traces of romance between the two, a sequence that indicates the intertwining between the narratives of the film. Then Stephen presented his idea to his advisor, at which point he is suggested to develop the mathematical foundations of his hypothesis: that the universe emerged from the explosion of a black hole. Such procedure is performed in only one sequence, in which the plans are superimposed quickly, producing the effect of speed and short temporality. The sequence that represents Stephen's scientific development was accompanied by classical music and was interrupted as the scientist fell to the floor, which leads him to the doctor who diagnosed his illness. The staging of the work for the mathematical development that would contribute to his hypothesis, even with a scene where Stephen erases the equation he wrote, indicates an activity that was easily carried out by a genius scientist.

At 27 minutes, after discovering his illness, (sequence 6), Stephen is represented with antisocial behaviors in an attempt to alienate people who want him close, a sequence that reinforces the image of the lone scientist, who does not need help. 
Although Hawking's behavior fits into a common representation of scientist, his action is understandable, since on the one hand it can be interpreted as altruistic, because he did not want the people he loved to suffer after his speculated death, and, on the other hand, selfish, because Stephen's only desire was to finish his doctoral work, regardless of the desire of other people to support or want to share the time with him. Thus, isolation did not occur because of a feeling of superiority or an inability to maintain adequate social relationships.

In the course of the plot, Stephen married Jane and defended his doctorate. During the defense, in the 39th minute (sequence 7), Sciama asked Hawking what would happen next, to which he replied: "[Hawking] To prove with a single equation, that time has a beginning. Wouldn't that be nice, Professor? The one simple, elegant equation to explain everything". The scene portrays the image that even after conquests, scientists remain ambitious and desire more and more, and also Hawking's determination to continue the work regardless of the difficulties posed by the illness.

During the defense celebration (sequence 8), his friends talked about how he was lazy and that he didn't dedicate himself as much as he should: "[Friend 1] It is astonishing he's the first person to receive his doctorate bearing in mind how little work he's been doing. [Friend 2] Work was the worst four-letter word for Stephen. At Oxford especially, he averaged an hour. An hour a day, he averaged. And now, here he is, the esteemed man. Astonishing levels of sloth". This representation reinforces the idea that he was a genius who did not need to strive for the development of his scientific work.

Even with the progress of his illness, Stephen never gave up fighting and dedicating himself to his research. His representation in the film is often related to that of a genius. At 48 minutes (sequence 9), Stephen, already in a slightly more advanced stage of the illness, was trying to put on a sweater by himself and it stuck on his head, allowing him to see his fireplace between the wool threads of the swater. As he saw the flames, he elaborated the idea that black holes emit radiation due to quantum phenomena: the Hawking radiation.

Soon after, during the presentation of his new theory (sequence 10), Stephen was prompted by a researcher, whose name was not mentioned, who stated that his theory was utter nonsense. Hawking stood firm, mocking his colleague's statement, asking if he had spoken anything wrong as he left the auditorium. Then, Isaak Khalatnikov, one of the big names in the study of hot universe and black holes, recognized Stephen's theory as something innovative. "[Khalatnikov] I came here today expecting to hear a lot of nonsense. I go home disappointed. The little one here has done it!". This speech by the professor highlights the disputes and contradictions present in the production of scientific knowledge.

According to Ferguson (2011), Hawking's proposal on radiation took place amid scientific disputes and collaborative work. The author claims that a graduate student in physics, named Jacob Bekenstein, had questioned a metaphor used by Hawking that the area of the black hole's horizon event is similar to entropy. For this young physicist, 
the area was not similar: it was entropy. In 1972 and 1973, irritated by what could be a misuse of his theory, Hawking joined James Bardeen and Brandon Carter, two fellow physicists, and together they formulated the four laws of black hole mechanics.

Also stated by Ferguson (2011), in 1973 Hawking decided to look at black holes under the perspective of quantum mechanics. In August of that year, the physicist went to Moscow and met with Yakov Borisovich Zel'dovich and his graduate student Alexander Starobinsky. The Russian physicists were developing a theory that black holes could emit particles, which would cause their rotation to slow down until it stopped completely and stopped emitting such particles. However, Hawking was not happy with the calculations and decided to do them himself. That done, he found a surprise: even non-rotating black holes emit particles at a steady rate.

After reviewing the calculations several times for errors, Hawking came to the conclusion that Bekenstein was correct. It is not possible to decrease the entropy of the universe just by "throwing" matter containing entropy into black holes as if they were large trash cans. From this, Hawking then described how the interaction between pairs of subatomic particles such as fermions and antimatter, photons and gravitons, would allow space for one of these particles to escape the event horizon. These particles would then give rise to the Hawking radiation theory (Ferguson, 2011).

The comparison between the story and the representation of Hawking in the film indicates particular forms of the production of the stereotype. In this case, the social contexts and the history itself are erased, especially the stages of formulation and development of ideas. By disregarding the action of other subjects, this erasure reinforces the stereotype of genius. In this sense, the representation of the film leads viewers to a mistaken view of the nature of science, in addition to contributing to an inadequate interpretation of the figure of the scientist.

In the following sequences, the director decided to focus on the protagonist's fight against his illness, exploring the family side and the support of his friends. Little was discussed about his work routine, but his achievements were extolled, such as the launch of his first book, "A brief history of time".

The film ends after 100 minutes (sequence 11), when Stephen told Jane, with a mocking smile, that he would go to the United States to receive yet another award. By using this expression, another award, he proved to be imponent and vain, reinforcing the representation that successful scientists are the center of the universe and that they should even be recognized for their greatness. The scientist's magnificence and vanity may not seem huge when we highlighted the context of the sequence, because the film reports that the relationship between Stephen and Jane was slowly falling apart. He acted in that manner as he tried to relieve a moment of tension between the couple.

\section{Concluding Remarks}

The purpose of this article was to analyze two biographical films by Stephen Hawking: "Hawking" and "The theory of everything", produced by BBC and Universal 
Studios, respectively, in order to identify the representations of the scientist present in the works. The analysis indicated that both films represented Stephen Hawking as a genius scientist, who does not need to make much effort to attain his achievements, which is even the most striking and evident representation of the works. In both films, the cosmologist is portrayed as carrying out complex research or corrections in a very short period of time and with few interactions with peers, which strengthens this image.

To organize the conclusions in a way to give more consistency to the arguments, we have compiled all the stereotypes found during the analysis, indicating the scenes in each film when Stephen Hawking was related to them.

Figure 6. Relationship between stereotypes and scenes/sequences of the films

\begin{tabular}{|c|c|c|}
\hline Stereotype & "Hawking" & “The Theory of Everything" \\
\hline $\begin{array}{l}\text { Isolation/ } \\
\text { Loneliness }\end{array}$ & $\begin{array}{l}\text { a. Birthday party. } \\
\text { b. Insight at Cambridge station. } \\
\text { c. Diluted throughout the film. }\end{array}$ & a. Refusal of help. \\
\hline Eccentric & $\begin{array}{l}\text { a. Birthday party. } \\
\text { b. Gathering in a Jazz bar. }\end{array}$ & Not identified in the film. \\
\hline $\begin{array}{l}\text { Maintainer } \\
\text { of scientific } \\
\text { discourse }\end{array}$ & $\begin{array}{l}\text { a. Birthday party. } \\
\text { b. Medical appointment. } \\
\text { c. Meeting with friends at the bar. } \\
\text { d. Lunch with Stephen, Penrose, Sciama and his } \\
\text { wife. }\end{array}$ & $\begin{array}{l}\text { a. May Ball. } \\
\text { b. Theory formulation. }\end{array}$ \\
\hline Arrogant & $\begin{array}{l}\text { a. Debate with Hoyle in the corridors. } \\
\text { b. Disputation of Hoyle's work. } \\
\text { c. Gathering in a Jazz bar. }\end{array}$ & Not identified in the film. \\
\hline Ironic & a. Hoyle's interview on a television program. & a. Presentation of his new theory. \\
\hline Genius & $\begin{array}{l}\text { a. Lunch with Stephen, Penrose, Sciama and his } \\
\text { wife. } \\
\text { b. Investigation of Hoyle's work. } \\
\text { c. Disputation of Hoyle's work. } \\
\text { d. Insight at Cambridge station. }\end{array}$ & $\begin{array}{l}\text { a. Ten impossible questions. } \\
\text { b. Idea for the research. } \\
\text { c. Theory formulation. } \\
\text { d. Celebrating doctoral } \\
\text { graduation. } \\
\text { e. Idea about Hawking Radiation. }\end{array}$ \\
\hline Mad & a. Gathering in a Jazz bar. & Not identified in the film. \\
\hline $\begin{array}{l}\text { Boring and } \\
\text { dull }\end{array}$ & Not identified in the film. & a. Party at the University. \\
\hline Ambitious & Not identified in the film. & a. Doctoral defense. \\
\hline $\begin{array}{l}\text { Imponent/ } \\
\text { Vain }\end{array}$ & Not identified in the film. & $\begin{array}{l}\text { a. Argument between Jane and } \\
\text { Stephen. }\end{array}$ \\
\hline
\end{tabular}


The table above shows a catalog of scenes from both films, organized according to the stereotypes found in them. As can be seen, in both features the stereotype of genius was the most found, followed by the stereotype of maintainer of scientific discourse, a fact that corroborates the interpretation that both films seek to represent Hawking as a genius. We did not identify similarity between the films with regard to other stereotypes, especially since some appear only once, which makes it impossible to define standards.

In "Hawking", the stereotype of a lone scientist is reinforced, having been found in three sequences. This is a point that indicates the representation of Hawking as a hero, since he is represented as a lone genius, that is, he does not need other people helping in the development of his work. In "The theory of everything", the broad representation of the stereotype genius, associated with the absence of negative stereotypes, such as eccentric, arrogant or mad, also reinforces the representation of the scientist as a hero.

When we point out the representation of genius, we do not in any way want to overshadow the fact that Hawking was a great scientist of the 20th century. We emphasize that we consider, from the beginning, that this representation obfuscates the work demanded for the development of his proposals. Therefore, the image of genius is based on an unexpected, sudden and abrupt scientific elaboration. The triangulation with Stephen's story indicates that the production of this stereotype was accompanied by the erasure of the historical and social contexts experienced by Hawking, so that the scientist was represented in the cinema as the only accountable for such deeds, without the representation of other subjects involved, as indicated in the consulted biographies.

The presence of this representation can even be an effect of the biographical film genre. Biopics have as their main feature the dramatic representation of some real subject. Generally, they seek the heroic representation of the character, which, in the case of the scientist, may be related to genius. We believe that this consideration can be deepened in a study of the representation of scientists in biographies, based on Barca (2005), who argues that since 2000 the scientist is represented as a hero.

If we analyze the duration of the sequences of the two films, we can see how they are substantially longer in "Hawking" than in "The theory of everything". Bearing in mind that the first was based on historical documents, while the second was based only on Jane Wilde's book, we believe that Hollywood production contributes more to the hero stereotype for Hawking. The scenes are short, demonstrating that the scientist needs little time to accomplish his deeds, which also implies that he does not make mistakes, or rarely makes mistakes, since he completes his tasks in a small chain of activities. Another point that validates this conclusion is that the negative stereotypes were not found in "The Theory of Everything": mad, eccentric and arrogant. This omission of personality traits is another way of constructing the image of a hero.

It was also possible to identify in the works other representations such as antisocial, maintainer of scientific discourse, mad, eccentric, ambitious, arrogant, successful, imponent and vain. By analyzing the social contexts in which the character was inserted and the sequences that led him to act in such ways, it is possible to understand the 
reasons for the actions classified in these representations. Therefore, although they seem antagonistic, these images do not deconstruct the heroic representation, although they indicate small breaks in the narrative for the production of the hero.

The narrative contexts analyzed showed that the representations are not fully stable and cohesive, but that they can carry contradictions that are determined by the subject's history and the social contexts experienced, as pointed out by Oliveira (2006).

The representation of the scientific community, in turn indicated aspects such as: boring field, arrogance, collective work, continuous work (perseverance) and disputes during the production of scientific knowledge. In addition, the scarcity of representation of female scientists, as well as scientists from other ethnic backgrounds (non-Caucasians), was evident in both films ${ }^{6,7}$. These results reinforce the most frequent representations of scientist indicated by the literature (Flicker, 2003; Jackson,2011; Ramos \& Olschowsky, 2009; Weingart et al., 2003).

We add the need to incorporate non-verbal elements in the analysis of representations of scientists and science in cinema. We recognize the difficulty of contemplating the different aspects of cinematic production, although the analysis of the production of scenes and sequences, as well as their association with excerpts from the soundtrack and text, has corroborated the classification of the scientist's actions in a given representation. Evidently, it is not possible to analyze all the elements present in the work in a scientific article, but considering these elements for analysis paves new ways for interpreting the relationship between cinema and scientific culture.

The analyzes indicate that biographical films featuring Stephen Hawking are based on the "spectacularization" of moments in the scientist's life to highlight his great scientific achievements or even the personal dramas experienced. When added to the considerations of Dijck (2006) about scientific documentaries on television, this finding indicates that representations of the scientist in cinema do not intend to portray the history of the scientist and science faithfully. Dijck (2006) points out that "the pictorial effect and speculative narrative mode may infiltrate and even dominate a television program, and yet producers choose to pay careful tribute to the realist features of the documentary genre" (p. 21). This same characteristic can be observed in the films analyzed, which were based, respectively, on historical documents and on the scientist's biography written by his first wife.

The results of our analysis can also be expanded and reconsidered based on Metz's (2008) contributions on scientific documentaries. Metz (2010) claims that the combination of reality and fiction is present in both science fiction and scientific documentaries, a fact that is problematic, since a break in the links between reality and scientific knowledge (meanings) is unlikely to be noticed. The author adds that

6 We believe that the dialogue about the representation of female scientists in films is very important, although this was not the focus of this work. In both films women are represented predominantly in secondary roles and outside the academic environment.

7 Another point we decided not to address is the representation of non-caucasian scientists. In both films this representation is almost nonexistent. 
"this uncoupling of scientific knowledge and its accurate presentation suggests that the science itself is subjunctive; that is, there is no (scientific) reality outside that which we as a culture believe" (Metz, 2008, p. 346). Such contributions are relevant because the biographies analyzed can also be understood as a combination of fiction and reality, whose boundaries are not well established and therefore can contribute to a misinterpretation of the history of science and the character. In the biographies, the distance between the representation and the real events of the story can favor a representation that is more based on the senses and values adopted about the subjects than on the events recorded historically, a fact that, in our understanding, can distort the character's history and promote inadequate representation of the STC.

Therefore, the results indicated that biographies, as well as other film genres, also represent scientists through stereotypes and distorted views of the nature of scientific work. We emphasize the need for a critical appreciation of films, which can be fostered by science education. Such appreciation should not aim at disqualifying or even belittling scientist's actions and achievements staged by cinema, but should contemplate other aspects, such as: the scientist's historical and cultural contexts; the conditions for scientific production; the values attributed to scientists present in the social imaginary; and also, the interests that permeate cinematic productions such as the commercialization of films.

The importance of this analysis also lies in understanding the elements that make up STC (Polino \& Castelfranchi, 2012), including external aspects such as the production of biographical texts and films, scientific themes, as well as the production of scientific knowledge. This understanding contributes to a more adequate interpretation of scientific culture, which is produced through various activities, social interactions and the consumption of artistic (cinema, literature, visual arts, theater, etc.) and communicative (scientific dissemination) productions. In this work, we stressed the influence of cinema as a way to foster public perception and imaginary of scientific culture.

\section{References}

Alcântara, A. Y., \& Lima, G. S. (2018). Categorias para o uso educativo de filmes com elementos científicos e tecnológicos. Revista de Ensino de Ciências e Matemática, 9(1), 85-104. https://doi.org/10.26843/rencima.v10i1.1571

Almeida, S. A., \& Lima E. C. C. (2016). Cientistas em revista: Einstein, Darwin e Marie Curie na Ciência Hoje das Crianças. Ensaio: Pesquisa em Educação em Ciências, 18(2), 29-47. http://dx.doi.org/10.1590/1983-21172016180202

Bangerter, A., \& Heath, C. (2004). The Mozart effect: Tracking the evolution of a scientific legend. British Journal of Social Psychology, 43, 605-623 https://doi. org/10.1348/0144666042565353 
Barbosa, L. C. A., \& Bazzo, W. A. (2013). O uso de documentários para o debate ciênciatecnologia-sociedade (CTS) em sala de aula. Ensaio: Pesquisa em Educação em Ciências, 15(3), 149-161. http://dx.doi.org/10.1590/1983-21172013150309

Barca, L. (2005). As múltiplas imagens do cientista no cinema. Comunicação \& Educação, X(1). http://www.revistas.usp.br/comueduc/article/viewFile/37507/40221

Candido, A. (1968). A personagem de Ficção (2a ed.). Editora Perspectiva.

Cazón, H. O. A., \& Oliveira, O. B. (2018). Relações com o saber na atividade de produção de documentário científico no ensino de biologia. Ensaio: Pesquisa em Educação em Ciências, 20, 1-21. https://doi.org/10.1590/1983-21172018200108

Cunha, M. B., \& Giordan, M. (2009). A Imagem da Ciência no Cinema. Química nova na escola, 31(1), 9-17. http://qnesc.sbq.org.br/online/qnesc31_1/03-QS-1508.pdf

Dijck, J. (2006). Picturizing science: The science documentary as multimedia spectacle. International JournalofCulturalStudies, 9(1). https://doi.org/10.1177/1367877906061162

Ferguson, K. (2011). Stephen Hawking, his life and work (1a ed.). Bantan Press.

Ferreira, J. D., \& Raboni, P. A. (2013). A ficção científica de Júlio Verne e o ensino de Física: uma análise de "Vinte Mil Léguas Submarinas". Caderno Brasileiro de Ensino de Física, 30, 84-103. https://doi.org/10.5007/2175-7941.2013v30n1p84

Flicker, E. (2003). Between brains and breasts-Women scientists in fiction film: On the marginalization and sexualization of scientific competence. Public Understanding of Science, 12(3), 307-318. https://doi.org/10.1177/0963662503123009

Gingras, Y. (2007). Henri Poincaré: The movie The Unintended Consequences of Scientific Commemorations. Isis, 98(2), 366-372. http://www.journals.uchicago.edu/ doi/abs/10.1086/521515

Gorp, B. V., Rommes, E., \& Emons, P. (2013). From the wizard to the doubter: Prototypes of scientists and engineers in fictions and non-fiction media aimed at Dutch children and teenagers. Public Understanding of Science, 23(6), 646-659. https://doi. org/10.1177/0963662512468566

Grego K. 2013. 'The physics you buy in the supermarkets'. Writing science for the general public: the case of Stephen Hawking. In S. Kermas and T. Christiansen (eds), The Popularization of Specialized Discourse and Knowledge across Communities and Cultures. Edipuglia, 149-172

Hawking, S. W. (1975). Particle creation by black holes. Communications in Mathematical Physics, 43, 199-220. https://doi.org/10.1007/BF02345020

Hawking, S. W. (1993). Hawking on the Big Bang and Black Holes. World Scientific Pub. Haynes, R. D. (2016). Whatever happened to the 'mad, bad' scientist? Overturning the stereotype. Public Understanding of Science, 25(1), 31-44. https://doi. org/10.1177/0963662514535689 
Jackson, J. K. (2011). Doomsday Ecology and Empathy for Nature: Women Scientists in "B" Horror Movies. Science Communication, 33(4), 533-555. https://doi. org/10.1177/1075547011417893

Johnston, K. M. (2011). Science fiction film: a critical introduction. Berg

Long, M., \& Steinke, J. Applegate, B., Lapinski, M. K., Johnson, M. J., \& Ghosh, S. (2014). Portrayals of Male and Female Scientists in Television Programs Popular Among Middle School-Age Children, Science Communication, 32, 356-382. https://doi. org/10.1177/1075547009357779

Marcelo, F. A., \& Ripoll, D. (2016). A educação ambiental pelas lentes do cinema documentário. Ciência \& educação, 22(4), 1045-1062. http://dx.doi.org/10.1590/1516731320160040013

Marsh, J. (Diretor). (2014). A teoria de tudo [Filme]. Universal Studios.

Martin, P. (Diretor). (2004). A história de Stephen Hawking [Filme]. BBC Two.

McKie, R. (2007, 1 de Agosto). A brief history of Stephen Hawking. Cosmos. https:// cosmosmagazine.com/physics/a-brief-history-of-stephen-hawking

Metz, A. M. (2008). A Fantasy Made Real: The Evolution of the Subjunctive Documentary on U. S. Cable Science Channels. Television \& New Media, 9(4), 333-348. https://doi. org/10.1177/1527476408315117

Oliveira, B. J. (2006). Cinema e imaginário científico. História, Ciências, Saúde Manguinhos, 13, 133-50. http://dx.doi.org/10.1590/S0104-59702006000500009

Penafria, M. (2009). Análise de Filmes - conceitos e metodologia(s). In VI Congresso SOPCOM. http://www.bocc.ubi.pt/pag/bocc-penafria-analise.pdf

Perez, V. S. (2012). Pessoa com deficiência = pessoa incapaz? Um estudo acerca do estereótipo e do papel da pessoa com deficiência nas organizações. Cadernos EBAPE. $B R, 10(4)$, artigo 6, 883-893. http://dx.doi.org/10.1590/S1679-39512012000400007

Piassi, L. P. (2013). Clássicos do cinema nas aulas de ciências - A física em 2001: uma odisseia no espaço. Ciência e Educação, 19, 517-534. https://doi.org/10.1590/S151673132013000300003

Piassi, L. P. C., \& Pietrocola, M. (2009). Ficção científica e ensino de ciências: para além do método de 'encontrar erros em filmes'. Educação e Pesquisa, 35, 525-540. https://doi. org/10.1590/S1517-97022009000300008

Polino, C., \& Castelfranchi, Y. (2012). Comunicación pública de la ciencia. Historia, prácticas y modelos. In E. Aibar, M. A.Quintanilla (Orgs.). Enciclopedia Ibero Americana de Filosofía: Ciencia, tecnología y sociedad, (Vol. 32) (pp. 351-378). Editorial Trotta.

Ramos, J., \& Olschowsky, J. (2009). As Representações Sociais de Cientistas em Filmes de Animação Infantil. XXXII Congresso Brasileiro de Ciências da Comunicação. http:// 
www.intercom.org.br/papers/nacionais/2009/resumos/R4-1225-1.pdf

Ramos, J. E. F., \& Piassi, L. P. C. (2017). O insólito e a física moderna: Interfaces didáticas do conto fantástico. Ciência \& Educação (online), 23, 163-180. http://dx.doi. org/10.1590/1516-731320170010010

Reznik, G., \& Massarani, L. (2019). Gender and science in animation: Analysis of the Anima Mundi Festival films. Journal of Science Communication, 18, p. A8. https://doi. org/10.22323/2.18020208

Roberts, A. (2016). The History of Science Fiction (2a ed.). Palgrave Macmillan.

Rodrigues, A., \& Assmar, E. M. L. Jablonski, B. (1999). Psicologia social. Vozes.

Rose, D. (2017). Análise de imagens em movimento. In Bauer, M. W., Gaskell, G (org.). Pesquisa qualitativa com texto, imagem e som: Um manual prático. Editora Vozes Limitada.

Sadoul, G. (1963.) História do cinema mundial: Das origens a nossos dias (Volume 1). Martins.

Santos, W. J., \& Silva, I. P. (2017). Potencialidades do filme de ficção Avatar para a alfabetização científica dos sujeitos no contexto da educação básica. Amazônia: revista de educação em ciências e matemática, 13(28), 51-63. http://dx.doi.org/10.18542/ amazrecm.v13i28.5290

Scalfi, G. A. M., \& Oliveira, M. M. (2015). Cine y ciencia: un análisis de los estereotipos presentes en la película infantil Frankenweenie, de Tim Burton. Alexandria, 8(2), 183197. http://dx.doi.org/10.5007/1982-5153.2015v8n2p183

Smith, M. K. (2001). 'What is non-formal education?', the encyclopedia of informal education. Infed.org. http://infed.org/mobi/what-is-non-formal-education/

Schmidt, B. B. (2014). Biografia: um gênero de fronteira entre a história e a literatura. In Rago, M., Gimenes, R.A. O. Narraropassado, repensar a história. Unicamp/IFCH,191-202.

Suppia, A. L. (2015). Em torno de cena e da sequência: problemas de categorização. Galáxia (São Paulo, Online), 30, 60-72. http://dx.doi.org/10.1590/1982-25542015220588

Weingart, P., Muhl, C., \& Pansegrau, P. (2003). Of power maniacs and unethical geniuses: science and scientists in fiction film. Public Understanding of Science, 12(3), 279-287. https://doi.org/10.1177/0963662503123006

White, M., \& Gribbin, J. (2002). Stephen Hawking, a life in science (3a ed.). Joseph Henry Press.

Zanetic, J. (2006). Física e Arte: Uma ponte entre duas culturas. Pro-Posições, 17(1), 39-58. https://www.fe.unicamp.br/pf-fe/publicacao/2344/49_dossie_zaneticj.pdf 
João Fernandes

University of São Paulo Institute of Physics São Paulo, São Paulo, Brazil joaof@if.usp.br

\section{${ }^{\circledR}$ Guilherme da Silva Lima}

Federal University of Ouro Preto Institute of Exact and Biological Sciences

Department of Physics Ouro Preto, Minas Gerais, Brazil glima@ufop.edu.br

Orlando Aguiar Jr.

Federal University of Minas Gerais Faculty of Education Department of Methods and Techniques of Education Belo Horizonte, Minas Gerais, Brazil oaguiar.ufmg@gmail.com

Editor in charge

Disclosure statement

No potential conflict of interest was reported by the authors.

Compliance with Ethical Standards

The authors declare this study was conducted following ethical principles. 